\title{
A comparative study between clonidine and dexmedetomidine in attenuation of pressor response during endotracheal intubation
}

\author{
Ganesh Nikam ${ }^{1}$, Madhukrishna N.,* \\ ${ }^{1}$ Associate Professor, ${ }^{2}$ PG Student, Dept. of Anaesthesia, Swami Ramanand Tirth Rural Government Medical College, \\ Ambajogai, Maharashtra, India
}

*Corresponding Author:

Email: puneeth.madhu@gmail.com

Received: $03^{\text {rd }}$ July, 2017

Accepted: $06^{\text {th }}$ November, 2017

\begin{abstract}
Aims: 1.To study and compare efficiency of clonidine and dexmedetomidine to reduce haemodynamic response i.e. attenuation of pressor response to laryngoscopy and tracheal intubation with single premedication dose.

2. To evaluate dose sparing effect of clonidine and dexmedetomidine on induction agent

Materials and Methods: 60 patients physical status ASA grade I and II were randomized into two groups: C and D ( $\mathrm{n}=30$ in each group). Group C received $1 \mu \mathrm{g} / \mathrm{kg}$ of clonidine while group D received $1 \mu \mathrm{g} / \mathrm{kg}$ of dexmedetomidine preoperatively over 10 minutes before induction through syringe infusion pump. Each patient was induced with injection Thiopentone sodium until loss of eyelash reflex. After check ventilation succinylcholine $2 \mathrm{mg} / \mathrm{kg}$ was given followed by tracheal intubation. Anaesthesia was maintained with $\mathrm{O}_{2}+\mathrm{N}_{2} \mathrm{O}(50: 50)$ and Vecuronium supplemented with isoflurane. Hemodynamic parameters were recorded.

Results: We observed no statistical difference in heart rate, blood pressure (systolic, diastolic and mean arterial pressure) between the two groups from baseline up to induction between two groups. Group C had higher readings of HR, SBP, DBP and MAP compared to group D after intubation upto $3 \mathrm{~min}$ which was statistically significant. Induction dose of thiopentone was lower in dexmedetomidine group and was statistically significant

Conclusion: Dexmedetomidine attenuated the hemodynamic pressor response and also reduces the dose requirement of thiopentone sodium and was superior to clonidine
\end{abstract}

Keywords: Clonidine, Dexmedetomidine, Premedication, Pressor response.

\section{Introduction}

Laryngoscopy and endotracheal intubation leads to tachycardia and hypertension due to sympathetic response. ${ }^{1}$ So, anaesthesiologist is always worried about this pressor response which leads to abnormal circulatory reaction which may be severe or prolonged. ${ }^{2}$

The circulatory response in the form of increased heart rate and raised blood pressure usually occurs for short duration and is unpredictable. This transient increase in blood pressure and pulse rate does not cause any harm in healthy individuals but may create problem in patients with myocardial insufficiency or cerebrovascular disease ${ }^{3}$ which may further cause complications like pulmonary oedema, myocardial infarction or cerebrovascular accidents. ${ }^{4,5}$

Pressor response is exaggerated in hypertensive patients even though made normotensive with antihypertensive medications ${ }^{6}$ and reflects intraoperatively with complications like myocardial infarction, acute left ventricular failure, ${ }^{7}$ arrhythmias and intracranial bleed. ${ }^{8}$

As intravenous induction agentsare not able to blunt stress response to laryngoscopy and endotracheal intubation, we have to add other pharmacological agents like lidocaine, sodium nitroprusside, calcium channel blockers, nitro-glycerine, beta blockers, inhalational anaesthetic agents, ACE inhibitors etc.
Clonidine and dexmedetomidine have been used for attenuating sympathetic response to laryngoscopy and endotracheal intubation. Both these drugs have $\alpha-1$ and $\alpha-2$ receptors agonist activity but dexmedetomidine has selective $\alpha-2$ receptor agonist activity which helps to blunt sympathetic response to laryngoscopy and tracheal intubation.

Clonidine is clinically useful due to sympatholytic, hypnotic, analgesic, sedative and anxiolytic effect without respiratory depression. ${ }^{9,10}$

So, we decided to compare the effect of single dose clonidine and dexmedetomidine in attenuating pressor response to laryngoscopy and intubation.

\section{Materials and Methods}

Our study was a prospective randomized double blinded study \&carried out in Department of Anaesthesiology. After taking permission from institutional ethical committee; patients were explained about the study and written informed consent was obtained. Sixty patients were selected for various elective surgical procedures with American association of Anaesthesia (ASA) physical status I and II.

\section{Inclusion criteria:}

1. Patients with ASA physical status I and II.

2. Irrespective of sex but aging between 18-60 years.

3. Patients posted for surgery under general anaesthesia. 


\section{Exclusion Criteria:}

1. Patient's refusal.

2. Known to drug allergy

3. Patients with difficult intubation

4. Pregnant and nursing females

Randomization done by computer generated table.

The anaesthesiologist administering drug and evaluating the patient was blinded to the drug injected.

Group C [Clonidine group]: $1 \mu \mathrm{g} / \mathrm{kg}$ iv in $20 \mathrm{ml}$ normal saline over 10mins.

Group D [Dexmedetomidine group]: $1 \mu \mathrm{g} / \mathrm{kgivin} 20$ $\mathrm{ml}$ normal saline over $10 \mathrm{mins}$.

Both the drugs were infused through syringe infusion pump. Systolic blood pressure (SBP), Diastolic blood pressure (DBP), Mean arterial pressure (MAP), heart rate and $\mathrm{SpO} 2$ was noted after $5 \mathrm{mins}$ of drug administration, and again at the completion of study drug infusion i.e. after 10 mins of drug administration.

SBP, DBP, MAP, Heart rate, $\mathrm{SpO} 2$ were noted at $1^{\text {st }}\left(\mathrm{AI} 1^{\text {st }} \min \right), 3^{\text {rd }}\left(\mathrm{AI} 3^{\text {rd }} \mathrm{min}\right), 5^{\text {th }}$ (AI $\left.5^{\text {th }} \min \right), 7^{\text {th }}(\mathrm{AI}$ $\left.7^{\text {th }} \mathrm{min}\right) \& 10^{\text {th }}$ minute after laryngoscopy \& intubation. Anaesthesia was maintained on $\mathrm{N} 2 \mathrm{O}+\mathrm{O} 2$, Isoflurane, Vecuronium and analgesics. IV fluids were administered as per requirement. At the end of surgical procedure, patients were reversed and extubated uneventfully. After clinical recovery patients were shifted to recovery room and observed for $2 \mathrm{hrs}$ for nausea, vomiting, bradycardia, hypotension, \& sedation. After assessing the Ramsay sedation score, patients were shifted to the ward and followed for another 24 hours; side effects if any were treated \& recorded.

\section{Side Effects}

1. Hypotension considered if systolic blood pressure $<90 \mathrm{mmHg}$.

2. Tachycardia was defined as heart rate $>100$ beats /min .

3. Bradycardia was defined as heart rate $<50$ beats / minute.

4. Dysrhythmia was defined as any rhythm other than sinus.

5. Hypertension when Systolic blood pressure $>150$ $\mathrm{mmHg}$ or diastolic blood pressure $>90 \mathrm{mmHg}$ for 60 seconds

Ramsay sedation scale is used as sedation score after five minutes of extubation.

\section{Statistical Method Employed}

Student $t$ test has been used to find the significance of study parameters on continuous scale within group (intragroup analysis) and between two groups (Inter group analysis). Fisher's exact test has been used to find the significance of study parameters on categorical scale between two groups.

\section{Results}

Table 1: Comparison of mean age, height, weight, gender \& ASA distribution in Both Groups

\begin{tabular}{|l|c|c|c|c|}
\hline Variables & $\begin{array}{c}\text { Group C } \\
(\text { Mean } \pm \text { SD })\end{array}$ & $\begin{array}{c}\text { Group D } \\
(\text { Mean } \pm \text { SD) }\end{array}$ & p value & Association is \\
\hline Age $(\mathrm{yrs})$ & $34.96 \pm 10.81$ & $36.23 \pm 10.65$ & 0.63 & NS \\
\hline Height $(\mathrm{cm})$ & $156.26 \pm 7.5$ & $155 \pm 6.18$ & 0.48 & NS \\
\hline SEX $(\mathrm{M} / \mathrm{F})$ & $17 / 13$ & $12 / 18$ & 0.3 & NS \\
\hline ASA $(\mathrm{I} / \mathrm{II})$ & $22 / 8$ & $26 / 4$ & 0.33 & NS \\
\hline Weight $(\mathrm{kg})$ & $56.2 \pm 5.89$ & $53.93 \pm 5.07$ & 0.11 & NS \\
\hline
\end{tabular}

$\mathrm{p}<0.05$ is Significant NS - Not Significant

Mean age, height, weight, genderdistribution \& ASA grading of both the groups showed no significant difference.

\section{Dose of Thiopentone in Both Groups}

The mean dose of thiopentone sodium $(\mathrm{mg} / \mathrm{kg})$ required for loss of eye lash reflex in group $\mathrm{C}$ and group D were $5.69 \pm 0.3$ and $4.6 \pm 0.3$ respectively and it was statistically highly significant decrease in dose of thiopentone sodium required for induction in dexmedetomidine group.

Comparison of hemodynamic changes between Clonidine group and Dexmedetomidine group

The baseline readings of these two groups were comparable. There was no difference in HR, SBP, DBP\& MAP between the two groups during the infusion of study drug. After laryngoscopy and intubation, the mean HR, SBP, DBP \& MAP at $1^{\text {st }}$ and $3^{\text {rd }}$ minute was increased in Group C than Group D and was statistically highly significant.

At $1^{\text {st }} \& 3^{\text {rd }}$ minute HR increased by $12 \%$ and $5.3 \%$ in Group C \& $1.7 \%$ at $1^{\text {st }}$ minute in Group D.

In Group $\mathrm{C}$ at $1^{\text {st }} \& 3^{\text {rd }}$ minute SBP increased by $10 \% \& 5 \%$, DBP increased by $16 \% \& 7.5 \%$ and MAP by $13 \%$ and $6.3 \%$, while Dexmedetomidine group showed no statistical significant difference between the baseline value and $1^{\text {st }}$ and $3^{\text {rd }}$ minute.

Also, there was no significant difference between the mean HR of the two groups at $7^{\text {th }}$ and $10^{\text {th }}$ minute after intubation but group D had lower mean SBP, DBP \& MAP compared to group $\mathrm{C}$ which was significant. 


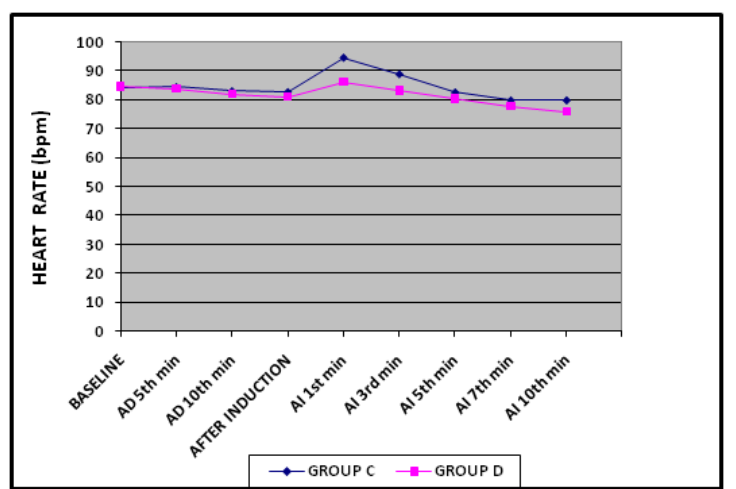

Fig. 1: Comparative status of mean heart rate changes between Clonidine group and Dexmedetomidine group AD - After drug administration; AI - After intubation $\}$

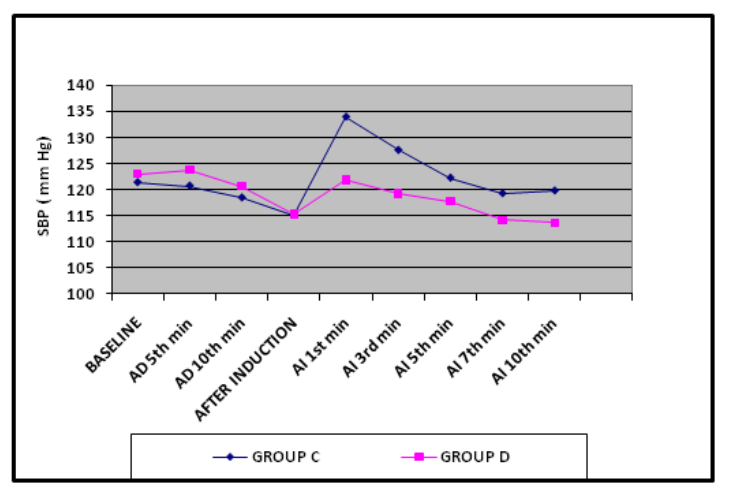

Fig. 2: Comparative status of mean Systolic Blood Pressure changes in between Clonidine and Dexmedetomidine group

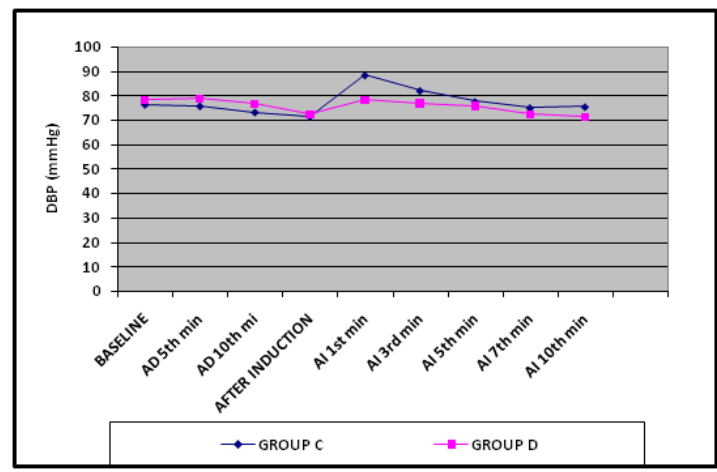

Fig. 3: Comparative status of mean Diastolic Blood Pressure changes in between Clonidine and Dexmedetomidine group

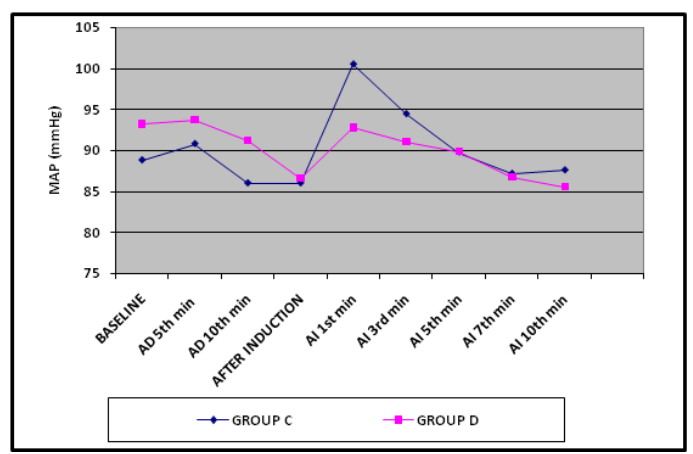

Fig. 4: Comparative status of Comparison of Mean Arterial Pressure changes in between Clonidine group and Dexmedetomidine group

\section{Side effects between clonidine and Dexmedetomidine group}

In clonidine group, none of the patients had side effects like bradycardia and hypotension. In group D, one patient had developed hypotension at third minute after intubation which was managed by decreasing inhalational agent and infusing intravenous fluids without inotropic support.

\section{Discussion}

In present modern era of anaesthesia, depending upon the surgical procedure, it can be given from local, regional blocks, selective nerve block to general anaesthesia.

General anaesthesia is gold standard and carried out with laryngoscopy and endotracheal intubation. Laryngoscopy and endotracheal intubation are associated with critical events because it accentuates significant sympatho-adrenal response in the form of tachycardia and hypertension. ${ }^{4}$

Dexmedetomidine is more potent $\alpha-2$ receptor agonist when compared to clonidine. ${ }^{11}$ So, dexmedetomidine is better drug of choice amongst $\alpha-2$ receptor agonist to suppress deleterioushemo dynamic response to laryngoscopy and endotracheal intubation.

Though dexmedetomidine is costly compared to clonidine, it significantly reduces drug requirement of anaesthetic agent with better haemodynamic blunting response to laryngoscopy and intubation ${ }^{12}$.

This study carried out to compare the effect of single dose of clonidine and dexmedetomidine to suppress pressor response to laryngoscopy and endotracheal intubation.

In view of demographic criteria and surgery both groups were comparable. In our study dose of clonidine and dexmedetomidine were used at dose of $1 \mathrm{ug} / \mathrm{kg}$ intravenously which based on observation in previous studies.

Various studies have been carried out with intravenous clonidine and dexmedetomidine to blunt stress response like tachycardia, hypertension to laryngoscopy and endotracheal intubation with various doses. 
Clonidine $1 \mathrm{mcg} / \mathrm{kg}$ iv attenuate haemodynamic response of laryngoscopy and endotracheal intubation (Kumkum etal). Dexmedetomidine $1 \mathrm{mcg} / \mathrm{kg}$ iv also attenuate stress response to laryngoscopy and endotracheal intubation in CABG patients (Ferdi etal). When clonidine and dexmedetomidine used in dose 1 $\mathrm{mcg} / \mathrm{kg}$ iv and compared, both showed significant reduction in myocardial contractility during laryngoscopy and intubation (Panda BK et al). ${ }^{12}$

In our study clonidine and dexmedetomidine in dose $1 \mathrm{ug} / \mathrm{kg}$ diluted to $20 \mathrm{ml}$ with normal saline and given intravenously over a period of $10 \mathrm{~min}$.

Mean dose of thiopentone sodium used for induction with clonidine was $5.69 \pm 0.3 \mathrm{mg} / \mathrm{kg}$ while it was $4.6 \pm 0.3 \mathrm{mg} / \mathrm{kg}$ with dexmedetomidine, which is statistically highly significant. So, there is significant reduction in thiopentone sodium requirement was seen in dexmedetomidine group compared to clonidine group. Dexmedetomidine is having anaesthetic sparing effect because of decrease in central noradrenergic transmission and specific $\alpha-2$ mediated analgesic and sedative property.

\section{Hemodynamic changes after laryngoscopy and intubation}

In our study groups, we found that dexmedetomidine had better control over pressor response to laryngoscopy compared to clonidine group; which is statistically significant. In clonidine group, there was statistically increase in HR, SBP, DBP, and MAP when compared to dexmedetomidine group.

Carabine UA et al and Tripathi DC etal shown that in clonidine group there was increase in HR and SBP at the time of intubation in dose of $1 \mathrm{ug} / \mathrm{kg}$ i.v and it did not prevent tachycardia and hypertensive response to laryngoscopy and intubation and extubation.

Kumkum et al observed that clonidine $1 \mathrm{ug} / \mathrm{kg}$ iv significantly attenuated and suppressed the haemodynamic response to laryngoscopy and intubation effectively as clonidine blunt the intraoperative haemodynamic response by decreasing the nociceptive transmission and decreasing noradrenaline concentration in serum.

Shanbagavalli $\mathrm{S}$ et al and Panda BK et al shown in their study that tachycardia response was higher in clonidine group than dexmedetomidine group which was statistically significant. Also dexmedetomidine causes significant decrease in myocardial contractility; dose dependant decrease in blood pressure and heart with decrease in serum norepinephrine concentration/which is comparable to our present study.

One can say that, use of intraoperative $\mathrm{Bi}$-spectral Index monitoring might have been more precise for the depth of anaesthesia and anaesthetic dose requirement and this might be limitation of our present study.

\section{Side Effects}

In clonidine group, no side effects were observed. One patient in group D had developed hypotension at 3rd minute after intubation; which was managed by decreasing inhalational agent, and infusing intravenous fluid without inotropes.

Bajwa $\mathrm{S}$ et al suggested that cardiac side effects of dexmedetomidine like bradycardia and sinus pause could have warranted the use of atropine. Panda BK cleared that clonidine and dexmedetomidine does not cause any serious side effect.

So, our present study was comparable with the finding of Bajwa $\mathrm{S}$ et al and Panda BK et al.

\section{Conclusion}

Here we can conclude with our study that Dexmedetomidine stands to better position when compared to clonidine for attenuation of pressor response tolaryngoscopy and endotracheal intubation and also decreases requirement of thiopentone sodium for induction of general anaesthesia .The hypotension caused by dexmedetomidine was not statistically significant so dexmedetomidine proved to be the agent of choice than clonidine.

\section{References}

1. Hung O. Editorials Understanding hemodynamic responses to tracheal intubation. 2001:723-6.

2. King B.D, Harris L.C, Greifenstein F.E, Elder J.D, Dripps R.D.Reflex circulatory responses to direct laryngoscopy and tracheal intubation performed during general anesthesia.Anesthesiology 1951;12:556-66.

3. Kovac AL. Controlling the haemodynamic response to laryngoscopy and endotracheal intubation. Journal of Clinical Anaesthesia 1996;8:63-79.

4. Prys-Roberts C, Green LT, Meloche R, Foex P. Studies of anaesthesia in relation to hypertension II. Haemodynamic consequences of induction and endotracheal intubation. Br J Anaesth 1971;43:531-47.

5. Dalton B, Guiney T. Myocardial ischemia from tachycardia and hypertension in coronary heart disease Patients undergoing anaesthesia. Boston: Ann Mtg American Society of Anaesthesiologists 1972. pp. 201-2.

6. Cedric Preys Roberts. Anaesthesia and hypertension. Br J Anaesth 1984; 56:711-24.

7. Fox EJ, Sklar GS, Hill CH, Villanue Var, King BD. Complications related to the pressor response to endotracheal intubation. Anaesthesiology. 1977; 47:5245.

8. Ronald D Miller. Miller's Anesthesia volume 2 Seventh edition 2010.

9. Jamadarkhana S, Gopal S. Clonidine in adults as a sedative agent in the intensive care unit. J Anaesthesiol Clin Pharmacol 2010;26:439-45.

10. Aho M, Lehtnen AM, Erkola O, Scheinin H, Lehtinen A, Kallio A, et al. The effect of intravenously administered dexmedetomidine on perioperative haemodynamics and isoflurane requirements in patients undergoing abdominal hysterectomy. Anaesthesiology. 1991;74:997-1002.

11. Tryba M, Gehling M.Clonidine: A potent analgesic adjuvant. Curr Opin Anaesthesiol 2002;15:511-7.

12. Panda BK, Singh P, Marne S, etal. A comparison study of Dexmedetomidine Vs Clonidine for sympathoadrenal response, perioperative drug requirements and cost 
analysis.asian pacific journal of tropical disease. 2012:16.

13. Stoelting RK. Circulatory changes during direct laryngoscopy and tracheal intubation: Influence of duration of laryngoscopy with or without prior lignocaine. Anaesthesiology .1977;47:381.

14. Dahlgreen N, Messeter K. Treatment of the stress response to laryngoscopy and intubation with Fentanyl. Anaesthesia. 1981;36:1022.

15. Martin DE, Rosenberg H, Aukburg SJ, Bartkowski RR, Edwards MW Jr, Greenhow DE, Klineburg PL. Low dose Fentanyl blunts circulatory responses to tracheal intubation. Anaesthesia Analgesia. $1982 ; 61: 680-4$.

16. Ebert JP, Pearson JD, Gelman S, Harris C, Bradley EL. Circulatory response to laryngoscopy. The comparative effects of Placebo, Fentanyl and Esmolol. Canadian Journal of Anaesthesia. 1989;36:301-6

17. Stoelting RK. Attenuation of blood pressure response to laryngoscopy and tracheal intubation with Sodium Nitroprusside. Anesthesia Analgesia. 1979;58:116-9.

18. Fossoulaki A, Kaniasis P. Intranasal administration of Nitroglycerine attenuates the pressor response to laryngoscopy and intubation of the trachea. Br J Anaesth. 1983;55:49-52.

19. Puri GD, Batra YK. Effect of Nifedepine on cardiovascular response to laryngoscopy and intubation. Br J Anaesth. 1988;60:579-81.

20. Nishikawa T, Naiki A. Attenuation of the pressor response to laryngoscopy and tracheal intubation with IV Verapamil. Act Anaesthesiologica Scandinavica 1989;33:232-5.

21. Fuji Y, Tanaka H, Saitoh Y, Toyooka H. Effects of Calcium channel blockers on circulatory response to tracheal intubation in hypertensive patients: Nicardipine vs Diltiazem. Canadian Journal of Anaesthesia. 1995;42:785-8

22. Prys-Roberts C, Foex P, Biro GP. Studies of anaesthesia in relation to hypertension versus adrenergic $\beta$ receptor blockade. Br J Anaesth 1973;.45:671-80.

23. Mc Cammon RL, Hilgenberg JC, Stoelting RK. Effect of Propranolol on circulatory responses to induction of diazepam- nitrous oxide anesthesia and to endotracheal intubation. Anesthesia Analgesia. 1981;60:579-83.

24. Chung KS, Sinatra RS, Chung JH. The effect of an intermediate dose of Labetalol on heart rate and blood pressure responses to laryngoscopy and intubation. Journal of Clinical Anaesthesia .1992;4:11-5.

25. Kulka PJ, Tryba M, Zenz M. Dose response effects of intravenous clonidine on stress response during induction of anaesthesia in coronary artery bypass graft patients. Anaesth Analg .1995;80:263-8.

26. Ralph Getler, Clieghton H Brown, Mitchel H, Silvius N. Dexmedetomidine: a novel sedative analgesic agent. Baylor University Medical Centre Proceedings. 2001;14. 